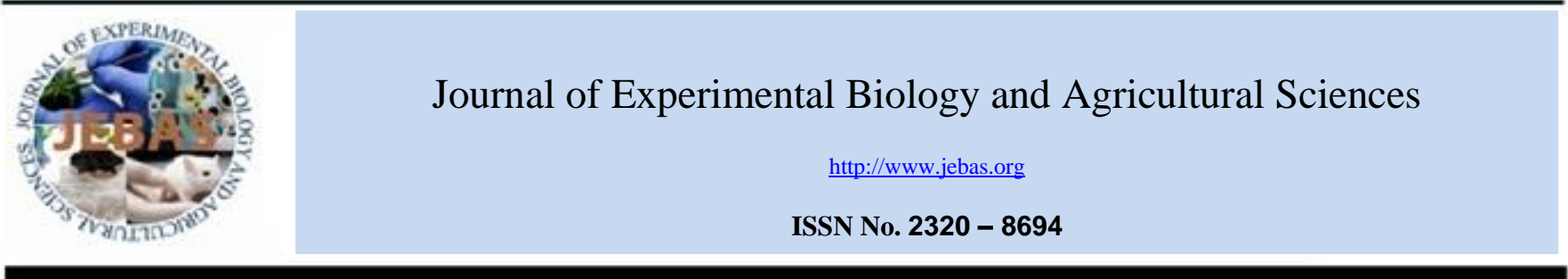

\title{
CHALLENGES OF PHYSIOTHERAPIST DURING PROSTHESIS REHABILITATION IN MALAYSIA
}

\section{Chong Li Chi, Vinodhkumar Ramalingam*}

Faculty of Health and Life Science, INTI International University, Nilai, Malaysia

Received - July 18, 2020; Revision - September 17, 2020; Accepted - October 29, 2020

Available Online - March 25, 2021

DOI: http://dx.doi.org/10.18006/2021.9(Spl-1-GCSGD_2020).S85.S94

\section{KEYWORDS \\ Prosthesis Rehabilitation \\ Quality of life (QOL) \\ Mortality Rate \\ Challenges}

* Corresponding author

E-mail: vinodh.ramalingam@newinti.edu.my (Vinodhkumar Ramalingam)

Peer review under responsibility of Journal of Experimental Biology and Agricultural Sciences.

Production and Hosting by Horizon Publisher India [HPI] (http://www.horizonpublisherindia.in/).

All rights reserved.

\begin{abstract}
The present study reported the challenges faced by the physiotherapist during prosthesis rehabilitation in Malaysia. Mortality due to lower limb amputation is a concern in recent days that can be improved by providing proper rehabilitation. However, challenges faced by the physiotherapist during rehabilitation are expected to affect the effectiveness of the rehabilitation. Hence, it is important to identify the possible challenges faced by the physiotherapist during prosthesis rehabilitation to take the necessary precautions for better outcomes. A total of 200 Malaysian physiotherapists who have experience in rehabilitating amputees were selected to participate in this online survey. The participants were requested to complete a selfadministered electronic questionnaire containing 20 questions. The present study reported a few challenges faced by the physiotherapists in Malaysia during prosthesis rehabilitation such as "encountering patient that refuse to perform exercises is common" (77\%), encountered high physical demand (81.5\%), encountering language barriers $(48.5 \%)$, patients often encounter difficulty in assessing health service $(63.5 \%)$ and encountering prosthesis problems (67\%). The barriers were inconsistent and complex, including patient factors, healthcare provider's factors, environmental factors, other factors. The study has highlighted challenges faced by the physiotherapists during prosthesis rehabilitation to raise awareness among physiotherapists and at the same time create ideas for specific health care practitioners to overcome the barriers, therefore shortening the length of rehabilitation and enhancing the effectiveness of the rehabilitation to lower the mortality.
\end{abstract}

All the articles published by Journal of Experimental Biology and Agricultural Sciencesare licensed under a Creative Commons Attribution-NonCommercial 4.0 International License Based on a work at www.jebas.org.

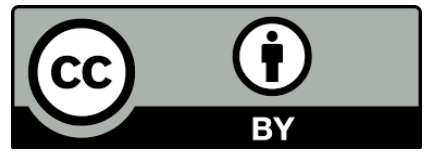




\section{Introduction}

WHO estimated that the number of disabled people in a developing country who need a prosthetic and orthotic device is $0.5 \%$ of the total population. The prediction also suggested that around 160,000 Malaysian need prosthetics and orthotic devices (Arifin et al., 2017; Karim \& Ming, 2020). Based on the study of Craig D. Murray, prosthesis usage is shown to have much deep personal meaning for amputees.

Therefore, it is suggested that health professionals play a very important role in preserving amputees' valued identities and allow them to manage their disability status (Murray, 2009). Mortality rates after lower limb amputation are respectively high according to Fortington et al. (2013) however; the mortality rate could be lowered by providing proper rehabilitation services. Studies indicated patients with amputation showed better survival rate, greater success with prosthesis fitting, more often return home, improvement in physical function, increased vitality, and reduction in body pain after numbers of inpatient rehabilitation (Pezzin et al., 2000; Christiansen et al., 2015; Ruth \& Bphty, 2019). Besides, the quality of life of persons with lower-limb amputation is reported to be maintained or improved through inpatient rehabilitation (Zidarov et al., 2009). Exercises to improve balance and coordination, range of motion, gait, cardiovascular endurance, strength, and prosthetic fit education are important for prosthetic rehabilitation (Imamphd et al., 2019).

However, the challenges faced by the physiotherapist during rehabilitation might affect the effectiveness of the rehabilitation (Afzal, 2017). Lower limb amputees fall incidence is the common challenge faced by the physiotherapist during prosthetic rehabilitation (Steinberg et al., 2019).

Whereby, effective prosthetic rehabilitation is vital in maintaining or improving the quality of life and the physical function of an amputated patient. Hence, it is important to find out the challenges faced by the physiotherapist during prosthesis rehabilitation to enhance the effectiveness of the rehabilitation. Numerous studies reported challenges faced by different health care providers in different areas (Litchfield \& MacDougall, 2002; Barber et al., 2015; Ennion \& Rhoda, 2016; Afzal, 2017).

However, there is very limited data shows the challenges faced by the physiotherapist during prosthesis rehabilitation. Steward et al. (1999) as well as Parnell \& Urton (2020) proposed the importance of identifying the possible challenges faced by therapists during rehabilitation to overcome future challenges. Hence, this study is to investigate the challenges faced by physiotherapists during prosthesis rehabilitation.
Also, the results may be used to raise awareness and create ideas among physiotherapists to overcome the barriers, thus enhancing the effectiveness of rehabilitation and lower the mortality rate (Fortington et al., 2013).

\section{Materials \& Methods}

This observational study use data of self-administered validated questionnaire to investigate the challenges faced by the physiotherapist during prosthesis rehabilitation in Malaysia. The online questionnaire consists of two sections. In the first section, demographic data included physiotherapists' gender; the level of certification; and working experiences with the year of service were displayed and the respondents were asked to select the responses from the list. In the second section, 20 questions regarding the challenges physiotherapists faced during prosthesis rehabilitation were listed and the respondents were instructed to rate the Likert scale based on their own direct experience. Score 1 and 2 on the Likert scale was considered as disagreeable and was categorized as 1 , score 3 on the Likert scale was considered as neutral and was categorized as 2, score more than 3 on the Likert scale was considered as agreeable and was categorized as 3 .

These 20 questions were categorized into 5 factors: patient factors, healthcare provider factors, cultural factors, environmental factors, and other factors. There are seven questions for patient factors, eight questions for healthcare provider factors, one question for cultural factors, and two questions for environmental factors and other factors respectively.

The physiotherapists working in Malaysia with at least a diploma level of certification and registered under the Malaysian Physiotherapy Association was considered as inclusion criteria. However, physiotherapists with working experience of fewer than 6 months were excluded. The minimum sample size of 377 was fixed based on the estimated population of therapists in Malaysia, approximately 19000 , by using the Raosoft sample size calculator. The online questionnaire was posted on the Malaysian physiotherapy Facebook page for a month from February until March 2020 after approval by the admin of the group. The research purpose was explained to every participant and informed consent was taken from respective participants before participation as shown in Figure 1. The study was approved by the research committee. IBM SPSS Statistics Version 21 was used to analyze the collected data. All descriptive information such as demographic data (name, age, gender, and qualification), working experience, and challenges that the physiotherapist faced during prosthesis rehabilitation were analyzed using central measures of tendency such as frequency, distribution, mean, and standard deviation. 
Table 1 Respondent characteristics

Male

Female

Educational level

Diploma

Degree

Master

Demographic

$\mathrm{n}(\%)$

$61(30.5 \%)$

$139(69.5 \%)$

\begin{tabular}{|cc|}
\hline & $78(39.0 \%)$ \\
\hline Diploma & $110(55.0 \%)$ \\
\hline Degree & $12(6.0 \%)$ \\
\hline Master & \\
\hline
\end{tabular}

Table 2 Challenges of physiotherapists presented in mean and standard deviation

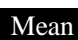

\section{D}

\begin{tabular}{lcc}
2.22 & .814 & Encountering patient with strong beliefs \\
\hline 2.05 & .813 & Encounter patient with racial preference/ stereotype \\
\hline 2.40 & .777 & Patients view physiotherapist without a specific professional identity
\end{tabular}

\begin{tabular}{lcc}
2.69 & .613 & Encountering patient that refuse to perform exercises \\
\hline 2.55 & .700 & Patient with obesity is more difficult to train when compared to the patient that is not obese \\
\hline 2.66 & .587 & Healthcare providers factors
\end{tabular}

\begin{tabular}{|c|c|c|}
\hline 2.38 & .799 & No coordination/ communication of efforts between multidisciplinary team \\
\hline 2.41 & .745 & Lack of job structure \\
\hline 2.51 & .695 & Lack of practice for prosthesis rehabilitation \\
\hline 2.38 & .805 & Workload during prosthetic rehabilitation is high \\
\hline 2.10 & .868 & Prevent fall incidence during prosthesis rehabilitation is difficult \\
\hline 2.19 & .811 & Feeling the burden of transdisciplinary \\
\hline 2.31 & .822 & Emotional stress is commonly faced by therapists \\
\hline \multirow[t]{2}{*}{2.77} & .530 & Encountered high physical demand \\
\hline & & Environmental factors \\
\hline 2.67 & .584 & Encounter with bigger gaps between follow-ups \\
\hline \multirow[t]{2}{*}{2.57} & .623 & Patients often encounter difficulty in assessing health service \\
\hline & & Cultural factor \\
\hline \multirow[t]{2}{*}{2.25} & .808 & Encountering language barriers \\
\hline & & Other factors \\
\hline 2.63 & .612 & Limited fund and resources \\
\hline 2.64 & .551 & Encountering prosthesis problems \\
\hline
\end{tabular}

Journal of Experimental Biology and Agricultural Sciences 


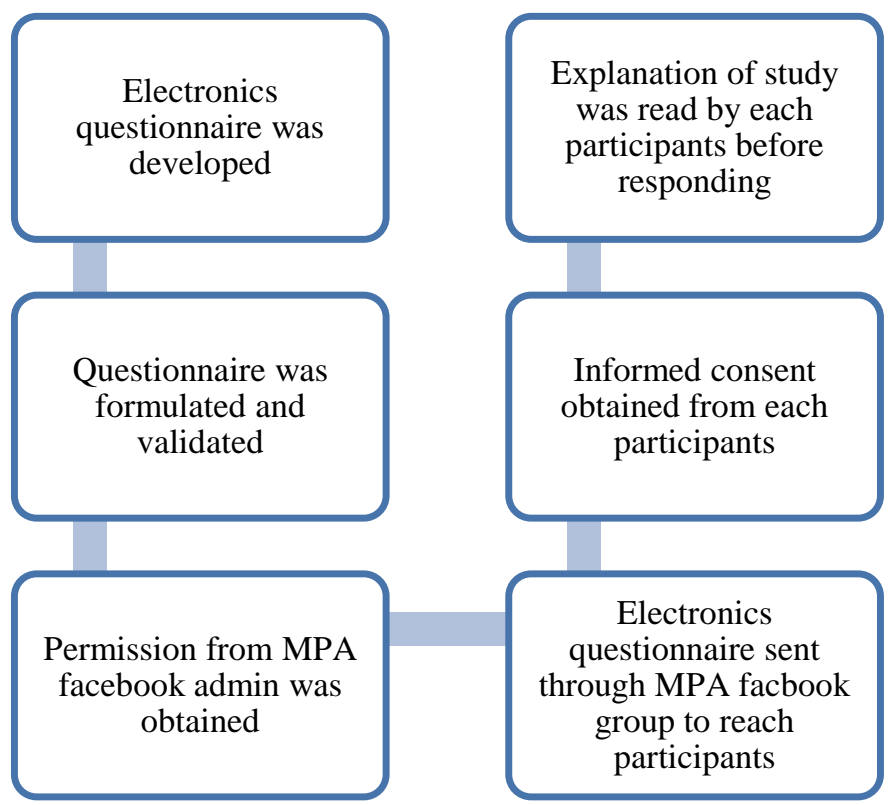

Figure 1 Flow chart for the process of data collection

Table 3 Patient factors presented in frequency, mean and standard deviation

\begin{tabular}{|ccccc|}
\hline Patient factors & Frequency $(\mathrm{n})$ & Disagreeable & Neutral & Agreeable \\
\hline Challenges & Mean (SD) & & $\mathrm{n}(\%)$ & \\
\hline Strong Beliefs & $2.22(.814)$ & $49(24.5 \%)$ & $59(29.5 \%)$ & $92(46.0 \%)$ \\
\hline Stereotype & $2.05(.813)$ & $61(30.5 \%)$ & $68(34.0 \%)$ & $71(35.5 \%)$ \\
\hline Mental illness & $2.40(.777)$ & $36(18.0 \%)$ & $48(24.0 \%)$ & $116(58.0 \%)$ \\
\hline No professional identity & $2.36(.808)$ & $42(21.0 \%)$ & $45(22.5 \%)$ & $113(56.5 \%)$ \\
\hline Refuse to exercise & $2.69(.613)$ & $16(8.0 \%)$ & $30(15.0 \%)$ & $154(77.0 \%)$ \\
\hline Obese patient & $2.55(.700)$ & $24(12.0 \%)$ & $42(21.0 \%)$ & $134(67.0 \%)$ \\
\hline Poor exercise adherence & $2.66(587)$ & $12(6.0 \%)$ & $43(21.5 \%)$ & $145(72.5 \%)$ \\
\hline
\end{tabular}

\section{Results}

\subsection{Respondent Characteristics}

In total, only 225 physiotherapists responded to the electronic questionnaire and 25 responses were excluded based on exclusion criteria. Finally, $200(n=200)$ responses were included for data analysis; the response rate was $88.89 \%$ among the respondents. Among 200 respondents, $30.5 \%$ were male and $69.5 \%$ were female, $39 \%$ were diploma graduates, $55 \%$ were degree graduates and only $6 \%$ were master graduates as shown in Table 1.

\subsection{Challenges faced by physiotherapists during prosthesis rehabilitation}

The mean and standard deviation were calculated individually for 20 challenges as shown in Table 2. Mean score out of 3.0 was calculated based on the scoring from the Likert scale (Beglar \& Nemoto, 2014). The challenges are categorized into patient factors, healthcare provider's factors, cultural factors, environmental factors, and other factors. Based on the data, it is evident that the majority of the physiotherapists in Malaysia have faced the challenges stated in the questionnaire.

\subsubsection{Patient factors}

Table 3 shows the frequency, mean and standard deviation for patient factors. All challenges under this category scored mean more than 2.0 hence, all of the challenges were considered as agreeable. The second challenge, encounter patients with racial preference/ stereotype is common, (eg: either prefer same race or vice versa) reported the lowest mean score. Among the attended respondents, $30.5 \%(n=61)$ voted for disagreeable, $34.0 \%(n=68)$ for neutral, and $35.5 \%(\mathrm{n}=71)$ for agreeable.

Further, the fifth challenge, encountering patient that refuse to perform exercises is common, reported the next higher mean score. In this challenge, $8.0 \% \quad(n=16)$ of the respondents voted for disagreeable, $15.0 \%(n=30)$ for neutral, and $77.0 \%(n=154)$ for agreeable. 
Table 4 Healthcare providers factors presented in frequency, mean and standard deviation

\begin{tabular}{|c|cccc|}
\hline Healthcare providers factors & Frequency $(\mathrm{n})$ & Disagreeable & Neutral & Agreeable \\
\hline Challenges & Mean (SD) & & n (\%) & $116(58.0 \%)$ \\
\hline No coordination between MDT & $2.38(.799)$ & $40(20.0 \%)$ & $44(22.0 \%)$ & $114(57.0 \%)$ \\
\hline Lack of job structure & $2.41(.745)$ & $31(15.5 \%)$ & $55(27.5 \%)$ & $123(61.5 \%)$ \\
\hline Lack of practice & $2.51(.695)$ & $23(11.5 \%)$ & $54(27.0 \%)$ & $111(55.5 \%)$ \\
\hline High workload & $2.38(.805)$ & $38(19.0 \%)$ & $51(25.5 \%)$ & $86(43.0 \%)$ \\
\hline Fall prevention & $2.10(.868)$ & $66(33.0 \%)$ & $48(24.0 \%)$ & $88(44.0 \%)$ \\
\hline Burden of MDT & $2.19(.811)$ & $50(25.0 \%)$ & $62(31.0 \%)$ & $107(53.5 \%)$ \\
\hline Emotional stress & $2.31(822)$ & $46(23.0 \%)$ & $47(23.5 \%)$ & $163(81.5 \%)$ \\
\hline High physical demand & $2.77(.530)$ & $10(5.0 \%)$ & $27(13.5 \%)$ & \\
\hline
\end{tabular}

Table 5 Cultural factors presented in frequency, mean and standard deviation

\begin{tabular}{|ccccc|}
\hline Cultural factor & Frequency (n) & Disagreeable & Neutral & Agreeable \\
\hline Challenges & Mean (SD) & & $\mathrm{n}(\%)$ & \\
\hline Language barrier & $2.25(.808)$ & $46(23.0 \%)$ & $57(28.5 \%)$ & $97(48.5 \%)$ \\
\hline
\end{tabular}

Table 6 Environmental factors presented in frequency, mean and standard deviation

\begin{tabular}{|ccccc|c|}
\hline Environmental factors & Frequency (n) & Disagreeable & Neutral & Agreeable \\
\hline Challenges & Mean (SD) & & $\mathrm{n}(\%)$ & \\
\hline Larger follow-up gaps & $2.67(.584)$ & $12(6.0 \%)$ & $41(20.5 \%)$ & $147(73.5 \%)$ \\
\hline Difficulty in assessing & $2.57(.623)$ & $14(7.0 \%)$ & $59(29.5 \%)$ & $127(63.5 \%)$ \\
\hline
\end{tabular}

Table 7 Other factors presented in frequency, mean and standard deviation

\begin{tabular}{|ccccc|}
\hline Other factors & Frequency $(\mathrm{n})$ & Disagreeable & Neutral & Agreeable \\
\hline Challenges & Mean (SD) & & $\mathrm{n}(\%)$ & \\
\hline Limited funds and resources & $2.63(.612)$ & $14(7.0 \%)$ & $46(23.0 \%)$ & $140(70.0 \%)$ \\
\hline Prosthesis problems & $2.64(.551)$ & $7(3.5 \%)$ & $59(29.5 \%)$ & $134(67.0 \%)$ \\
\hline
\end{tabular}

\subsubsection{Healthcare provider factors}

Table 4 shows the frequency, mean and standard deviation for healthcare providers factors. All challenges under this category scored mean more than 2.0 hence, all of the challenges were considered as agreeable. The twelfth challenge, prevent fall incidence during prosthesis rehabilitation is difficult, gained the lowest mean score. $33.0 \%(\mathrm{n}=66)$ of the respondents voted for disagreeable, $24.0 \%(n=48)$ for neutral, and $43.0 \%(n=86)$ for agreeable. Whereas, the fifteenth challenge encountered high physical demand, scored the highest mean score as $5.0 \%$ of the respondents $(n=10)$ voted for disagreeable, $13.5 \% \quad(n=27)$ for neutral, and $81.5 \%(n=163)$ for agreeable.

\subsubsection{Cultural factor}

Table 5 shows the frequency, mean and standard deviation for the cultural factor. Encountering language barriers is common; this challenge was considered agreeable as the mean reported score was more than 2.0. On this, $23.0 \%(n=46)$ of respondents voted for disagreeable, $28.5 \%(n=57)$ for neutral, and the rest $48.5 \%(n=97)$ for agreeable.

\subsubsection{Environmental factors}

Table 6 shows the frequency, mean and standard deviation for environmental factors. All challenges under this category scored mean more than 2 hence, all of the challenges were considered as agreeable. Encounter with bigger gaps between follow-ups (>2 weeks) due to unforeseen circumstances is common; this challenge reported the third-highest mean score among all of the challenges. Among 200 respondents, $73.5 \%(n=147)$ voted for agreeable.

The eighteenth challenge, patients often encounter difficulty in assessing health service, $7.0 \%(n=14)$ of the respondents voted for disagreeable, 29.5\% (n=59) for neutral, and $63.5 \%(n=127)$ for agreeable.

\subsubsection{Other factors}

Table 7 shows the frequency, mean and standard deviation for other factors. Limited funds and resources, this challenge is considered as agreeable as the mean score was more than 2.0. Among 200 respondents, $7.0 \%(n=14)$ of the respondents voted for disagreeable, $23.0 \% \quad(n=46)$ for neutral, and $70.0 \% \quad(n=140)$ for agreeable. The twentieth challenge, encountering prosthesis problems are common, this challenge was considered as agreeable as well and among the replied respondents, $3.5 \%(n=7)$ of the respondents voted for disagreeable, $29.5 \% \quad(n=59)$ for neutral, and $67.0 \%(n=134)$ for agreeable. 


\section{Discussion}

The purpose of this study was to investigate the challenges faced during prosthesis rehabilitation from the perspective of physiotherapists. The challenges identified can be categorized into five categories: patient factors, healthcare provider's factors, cultural factors, environmental factors, and other factors.

This study was unique in its use of quantitative research principles to investigate the barrier during prosthesis rehabilitation in Malaysia. There were several qualitative studies have explored the barriers faced by different groups of healthcare providers from different areas, however, few studies have explored physiotherapists' perceptions related to prosthesis rehabilitation in Malaysia. Therefore, the present study results provide an exceptional insight into prosthesis rehabilitation to complement the current literature.

\subsection{Patient factors}

In this study, $46.0 \%$ of the respondents experienced treating a patient with strong belief during prosthesis rehabilitation (Table 3). External evidence in support of this finding is available from a recent study in South Africa (Ennion \& Rhoda, 2016). According to this, traditional healers were recognized as part of the multidisciplinary team (MDT) and to work closely with the hospitals. The amputation and mortality rate could be lowered if traditional healers are to be recognized as part of the MDT and trained to refer the patients to hospitals. However, many patients chose to believe that illness was related to bewitchment and sought help from traditional healers to appease their ancestors and remove the "curse". This greatly reduces their trust and adherence to western medicine and rehabilitation (Ennion \& Rhoda, 2016). Among the replied respondents, $35.5 \%$ of the respondents voted agreeable for the statement "racial preference/ stereotype" as shown in Table 3, this indicated that physiotherapists involved in prosthesis rehabilitation in Malaysia did experience treating patients with racial preference or stereotype. This finding is also supported by the study done in South Africa regarding prosthesis rehabilitation (Ennion \& Rhoda, 2016), however, most of the physiotherapists in Malaysia is from local instead of the foreign country. Furthermore, the Malaysian concept is to strengthen relationships and cooperation among the multi-ethnic people in this country. According to Prime Minister, One Malaysia concept "we stand, we think, and we act as Malaysians and we take actions based on the needs of all ethnic groups in our country" (Zainal \& Salleh, 2010). Hence, this might not be a big challenge for prosthesis rehabilitation.

Table 3 shows that $58.0 \%$ and $67.0 \%$ of the respondents agreed with treating patients with mental illness and obesity is difficult. Similarly, Potter et al. (2003) interviewed physiotherapists working in the Perth metropolitan area, reported that patients with physical and psychological problems are hard to manage.

The reason behind the difficulty in treating an obese patient is owing to low levels of physical activity with poor adherence to exercise interventions as well as lack of motivation (You et al., 2012; Firth et al., 2016). Furthermore, Potter et al. (2003) highlighted that, physiotherapist skill and psychological skill training need to be trained and suggested that communication as well as behaviour modification strategies for improving and assisting the work for patients with difficultly. However, a study by Vivas et al. (2017) reported that obesity does not show a disadvantage with regards to validated outcomes, such as the 2-min walk test, L-test or SIGAM score at discharge after inpatient amputation rehabilitation, hence obesity should not be a barrier to offering inpatient rehabilitation for amputation patients.

In this study, $56.5 \%$ of the respondents agreed with patients' view of therapists without specific professional identity (Table 3). This finding is corroborated by a study done in the UK by Timmons and East regarding uniforms, status, and professional boundaries in hospitals (Timmons \& East, 2011). This might result in a sense of loss and disempowerment by the therapist, hence reducing their commitment during rehabilitation. As shown in Table 3, 77.0\% of the respondents and $72.5 \%$ of the respondents agreed for patients refuse to perform the exercise, and the patient's adherence to exercise is poor.

This finding is supported by a study done by Parry et al. (2017) regarding factors that affect the implementation of early rehabilitation into intensive care unit practice. The reason behind this might be owing to the patient's motivation and intake of sedative medications. To overcome this barrier, communication and education with patients and their families are very important; hence it is encouraged to involve patients and family in setting individualized patient goals.

\subsection{Healthcare provider's factors}

In this study, the majority of the respondents (44.0\%) agree that there is a lack of coordinated effort among MDT (Table 4). Ennion \& Rhoda, (2016) found that the members of the MDT might not know their roles. For instance, most health professionals do not include and recognize amputees as members of MDT; surgeons spend time only in performing surgery instead of discussing patient goals and rehabilitation outcomes; as well as barriers between prosthetists and physiotherapists. Team working is considered essential, as a wide range of knowledge and skills is required to diagnose and assess impairments; activity limitations, and participation restrictions; as well as select treatment options (Neumann et al., 2010). According to Neumann et al. (2010) and Clarke (2013), the lack of MDT approach might negatively affect 
the outcome of rehabilitation and cause prosthesis problems due to inadequate rehabilitation for prosthetic fitting.

Among the respondents, $57.0 \%$ and $61.5 \%$ of the respondents agreed that there is a lack of job structure and lack of practice for prosthesis rehabilitation respectively as shown in Table 4. Afzal (2017) looked at the major challenges faced by the physiotherapy profession is expanding its role in health, prevention, and wellness service, and found a lack of job structure and lack of practice for prosthesis rehabilitation. The reason behind the lack of practice for prosthesis rehabilitation might be owing to different factors, a variety of levels of amputation as well as personal and environmental factors. A recent study regarding physiotherapy and rehabilitation approaches to lower-limb amputation by Ülger et al. (2007) suggested that the applications of various physiotherapy methods for prosthesis rehabilitation. Moreover, published evidence-based clinical guidelines for the physiotherapy management of adults with lower limb prosthesis which are readily accessed online can be used as a source of reference (Broomhead et al., 2012).

In this study, $43.0 \%$ of the respondents voted agreeable for prevention of fall are difficult (Table 4). This finding has not been reported widely in the literature. However, the study by Pauley et al. (2006) highlighted fall incidents among patients with lower limb amputation during inpatient rehabilitation is as high as $20 \%$ among all the amputees involved in the inpatient rehabilitation. Also, the same authors predict that older age, the greater number of comorbidities, cognitive impairment, and the use of a greater number of medications can increase the incidence of falls (Steinberg et al., 2019). Among the tested respondents, $44 \%$ of the respondents claimed that there is the burden of transdisciplinarity as shown in Table 4. This finding is also similar to the study carried out in South Africa on prosthesis rehabilitation.

According to Ennion \& Rhoda, younger inexperienced therapists might be confused about transdisciplinarity and feel the burden. For instance, crossing the boundaries of discipline-specific scopes of practice considered as illegal implications especially when an injury to the patient occurs (Ennion \& Rhoda, 2016).

As shown in Table 4, more than half of the respondents voted agreeable for high workload and emotional stress. Furthermore, $81.5 \%$ of the respondents voted agreeable for high physical demand. According to Pavlakis et al. (2010), physiotherapist plays an important role during the rehabilitation process, therefore emotional stress is susceptible for a physiotherapist. This study also suggested that low salary, employment sector, age group, and jobrelated stress will lead to burnout syndrome and hence affect the effectiveness of the rehabilitation.

\subsection{Cultural factor}

Among the respondents, $48.5 \%$ experienced a language barrier during prosthesis rehabilitation in this study (Table 5). These results are in agreement with the findings of Ennion \& Rhoda (2016), language barrier is also reported during prosthesis rehabilitation in South Africa. The reason behind this was owing to the majority of the healthcare professionals were English speaking, however, only patients from several areas can speak and understand English.

Patients who are older, less educated, low income, and underinsured are believed to be low English proficient (LEP) (Wilson et al., 2005). English proficient status patients negatively affected the rehabilitation team's ability to diagnose, counsel, educate, and provide quality rehabilitation service (Neumann et al., 2010; Clarke, 2013).

A study by Wilson et al, suggested that an increasing number of language-concordant physicians might reduce language barriers and improve the quality of care for LEP patients (Wilson et al., 2005).

\subsection{Environmental factors}

In this study, the majority of the respondents $(73.5 \%, 63.5 \%)$ voted for agreeable to both bigger follow-up gaps and difficulties to assess healthcare service (Table 6). This finding is supported by a study conducted in South Africa as well. Patients often struggled to follow up for prosthesis rehabilitation after discharge from inpatient rehabilitation due to some unforeseen circumstances such as lack of transportation and bad weather. These circumstances require patients to make use of public transport or request somebody to send them to attend clinics or follow-up at the hospital, which the majority of the patients refused to do so to avoid troubling others (Ennion \& Rhoda, 2016; Stuckey et al., 2020).

\subsection{Other factors}

Respondents $(70.0 \%)$ in this study highlighted that there are limited funds and resources when providing prosthesis rehabilitation (Table 7). Previous studies have noted that there is a lack of sufficient prosthetists being trained to meet the growing demands of persons with lower limb amputation in developing countries (Pearlman et al., 2008; Sanders, 2020). Other than that, the study carried out in South Africa on prosthesis rehabilitation and the recent guidelines on "rural-proofing policy and resourcing for health in rural areas" also reported similar results (RuralProofing for Health: Guidelines, 2015; Ennion \& Rhoda, 2016). Considering the increased demand for rehabilitation services in rural settings owing to the increased incidence of disabilities, however, few rehabilitation therapists were employed hence the 
shortage of therapy staff is to be a concerned (Wilson et al., 2009; Sanders, 2020). This problem is then leading to high workload $(55.5 \%)$, emotional stress $(53.5 \%)$, and high physical demand $(81.5 \%)$ to the therapists in charge, where the majority of the respondents in this study were also agreed with the statement (Table 4). As a result of these stresses, the therapist in charge might be discouraged to continue to work in that setting or suffer burnout (Ennion \& Rhoda, 2016). Among the respondents, 67.0\% have experienced treating patients with prosthesis problems as shown in Table 7. External evidence in support of the present study finding is the study done in the Netherlands regarding the functional performance, participation, and autonomy after discharge from prosthetic rehabilitation are their autonomy outdoors and family role (Van Twillert et al., 2014). It is proved that the patients' satisfaction level towards their prosthetic limbs can affect rehabilitation interventions (Webster et al., 2012).To overcome this barrier, a study done in Australia proved that introduction of the interim prosthetic program (IPP) successfully reduced time to all primary rehabilitation (Hordacre et al., 2013).

\section{Conclusion}

Prosthesis rehabilitation was a vital process for amputees to lower the mortality rate and improve or maintain the general quality of life of the patient. There were several barriers faced by physiotherapists during prosthesis rehabilitation, which can be categorized into patient factors, healthcare provider's factors, cultural factors, environmental factors, as well as other factors. This study also created some ideas on modifications that could be done to facilitate prosthesis rehabilitation, including enhanced planning of a comprehensive amputation rehabilitation program, increased investment, improved planning and communication between medical units involved. Furthermore, recruiting different races and incorporating different languages in rehabilitation could be a viable option to address the identified challenges during prosthesis rehabilitation.

\section{Acknowledgement}

The authors thank all the respondents for their valuable feedback through the electronic survey of the present study. Also, special thanks to the Malaysian physiotherapy association for the acceptance to use their Facebook page.

\section{References}

Afzal F (2017) Major Challenges the Physiotherapy Profession Faces in Expanding its Role in Health, Prevention, and Wellness Services. Journal of Physiotherapy \& Physical Rehabilitation 02(04): 4-6. https://doi.org/10.4172/2573-0312.1000151.

Arifin N, Hasbollah HR, Hanafi MH, Ibrahim AH, Wan Abdul Rahman WA, Che Aziz R (2017) Provision of prosthetic services following lower limb amputation in Malaysia. Malaysian Journal of Medical Sciences 24(5): 106-111. https://doi.org/10.21315/mjms2017.24.5.12.

Barber EA, Everard T, Holland AE, Tipping C, Bradley SJ, Hodgson CL (2015) Barriers and facilitators to early mobilisation in Intensive Care: A qualitative study. Australian Critical Care 28(4): 177-182. https://doi.org/10.1016/j.aucc.2014.11.001.

Beglar D, Nemoto T (2014) Developing Likert-scale questionnaires. JALT2013 Conference Proceedings: 1-8.

Broomhead P, Clark K, Dawes D, Hale C, Lambert A, Quinlivan D, Randell T, Shepherd R, Withpetersen J, Rehabilitation (2012) Evidence Based Clinical Guidelines for the Physiotherapy Management of Adults with Lower Limb Prostheses Amputee Rehabilitation CSP Clinical Guideline 03. 03(November).

Christiansen CL, Fields T, Lev G, Stephenson RO, StevensLapsley JE (2015) Functional Outcomes After the Prosthetic Training Phase of Rehabilitation After Dysvascular Lower Extremity Amputation. Physical Medicine and Rehabilitation 7(11): 1118-1126. https://doi.org/10.1016/j.pmrj.2015.05.006.

Clarke DJ (2013) The role of multidisciplinary team care in stroke rehabilitation. Progress in Neurology and Psychiatry 17(4): 5-8. https://doi.org/10.1002/pnp.288.

Ennion L, Rhoda A (2016) Roles and challenges of the multidisciplinary team involved in prosthetic rehabilitation, in a rural district in South Africa. Journal of Multidisciplinary Healthcare 9: 565-573. https://doi.org/10.2147/JMDH.S116340.

Firth J, Rosenbaum S, Stubbs B, Gorczynski P, Yung AR, Vancampfort D (2016) Motivating factors and barriers towards exercise in severe mental illness: A systematic review and metaanalysis. Psychological Medicine 46(14): 2869-2881. https://doi.org/10.1017/S0033291716001732.

Fortington LV, Geertzen JHB, Van Netten JJ, Postema K, Rommers GM, Dijkstra PU (2013) Short and long term mortality rates after a lower limb amputation. European Journal of Vascular and Endovascular Surgery 46(1): 124-131. https://doi.org/10.1016/j.ejvs.2013.03.024.

Hordacre B, Birks V, Quinn S, Barr C, Patritti BL, Crotty M (2013) Physiotherapy rehabilitation for individuals with lower limb amputation: A 15-year clinical series. Physiotherapy Research International 18(2): 70-80. https://doi.org/10.1002/pri.1529.

Imamphd B, Miller WC, Finlayson HC, Eng JJ, Jarus T (2019) Lower limb prosthetic rehabilitation in Canada: A survey study. 
Physiotherapy Canada 71(1):

https://doi.org/10.3138/ptc.2017-39.

Karim HHA, Ming CP (2020) Characteristics and prosthesis usage of amputees attending medical rehabilitation services in Malaysia. Medical Journal of Malaysia 75(5): 519-524.

Litchfield R, MacDougall C (2002) Professional issues for physiotherapists in family-centred and community-based settings. Australian Journal of Physiotherapy 48(2): 105-112. https://doi.org/10.1016/S0004-9514(14)60204-X.

Murray CD (2009) Being like everybody else: The personal meanings of being a prosthesis user. Disability and Rehabilitation 31(7): 573-581. https://doi.org/10.1080/09638280802240290.

Neumann V, Gutenbrunner C, Fialka-Moser V, Christodoulou N, Varela E, Giustini A, Delarque A (2010) Interdisciplinary team working in physical and rehabilitation medicine. Journal of Rehabilitation Medicine 42(1): https://doi.org/10.2340/16501977-0483.

Parnell B, Urton M (2020) Rehabilitation Nursing Challenges for Patients With Lower Limb Amputation. Rehabilitation Nursing: the Official Journal of the Association of Rehabilitation Nurses.

Parry SM, Huang M, Needham DM (2017) Evaluating physica functioning in critical care: considerations for clinical practice and research. Criticle Care 21: 249. https://doi.org/10.1186/s13054017-1827-6.

Pauley T, Devlin M, Heslin K (2006) Falls sustained during inpatient rehabilitation after lower limb amputation: Prevalence and predictors. American Journal of Physical Medicine and Rehabilitation 85(6): 521-535 https://doi.org/10.1097/01.phm.0000219119.58965.8c.

Pavlakis A, Raftopoulos V, Theodorou M (2010) Burnout syndrome in Cypriot physiotherapists: a national survey. BMC Health Services Research 10:63.

Pearlman J, Cooper R, Krizack M, Lindsley A, Wu Y, Reisinger K, Armstrong W, Casanova H, Chhabra H, Noon J (2008) Lowerlimb prostheses and wheelchairs in low-income countries: An Overview. IEEE Engineering in Medicine and Biology Magazine 27(2): 12-22. https://doi.org/10.1109/EMB.2007.907372.

Pezzin LE, Dillingham TR, MacKenzie EJ (2000) Rehabilitation and the long-term outcomes of persons with trauma-related amputations. Archives of Physical Medicine and Rehabilitation 81(3): 292-300. https://doi.org/10.1053/apmr.2000.0810292.
Rural-proofing for health guidelines (2015) A guide to accounting for rural contexts in health policy, strategic planning and resourcing $\mathrm{r}$ u $\mathrm{r}$ a $1 \mathrm{~h}$ e a $1 \mathrm{t} \mathrm{h}$ rural-proofing health policy and strategic planning a systematic process. www.rhap.org.za.

Ruth H, Bphty B (2019) Functional Outcomes of People with Lower Limb Amputation Following Inpatient Rehabilitation. Available

at https://espace.library.uq.edu.au/view/UQ:0e9c5f7/s33420688_final _thesis.pdf?dsi_version=36e06966d943259242566cc8b79456de access on 25th May 2020.

Sanders P, Wadey R, Day M, Winter S (2020) Prosthetic Rehabilitation in Practice: An Exploration of Experiential Knowledge in the Multidisciplinary Team. Qualitative Health Research 104973232093327. doi:10.1177/1049732320933272.

Steinberg N, Gottlieb A, Siev-Ner I, Plotnik M (2019) Fall incidence and associated risk factors among people with a lower limb amputation during various stages of recovery-a systematic review. Disability and rehabilitation 41(15): 1778-1787.

Steward O, Schauwecker PE, Guth L, et al. (1999) Genetic approaches to neurotrauma research: opportunities and potential pitfalls of murine models. Experimental Neurology 157:19-42.

Stuckey R, Draganovic P, Ullah MM, Fossey E, Dillon MP (2020) Barriers and facilitators to work participation for persons with lower limb amputations in Bangladesh following prosthetic rehabilitation. Prosthetics and Orthotics International 030936462093432. doi:10.1177/0309364620934322.

Timmons S, East L (2011) Uniforms, status and professional boundaries in hospital. Sociology of Health and Illness 33(7): 1035-1049. https://doi.org/10.1111/j.1467-9566.2011.01357.x.

Ülger Ö, Yıldırım Şahan T, Çelik SE (2018) A systematic literature review of physiotherapy and rehabilitation approaches to lower-limb amputation. Physiotherapy Theory and Practice 34(11): 821-834. https://doi.org/10.1080/09593985.2018.1425938.

Van Twillert S, Stuive I, Geertzen JHB, Postema K, Lettinga AT (2014) Functional performance, participation and autonomy after discharge from prosthetic rehabilitation: Bariers, facilitators and outcomes. Journal of Rehabilitation Medicine 46(9): 915-923. https://doi.org/10.2340/16501977-1846. 
Vivas LLY, Pauley T, Dilkas S, Devlin M (2017) Does size matter? Examining the effect of obesity on inpatient amputation rehabilitation outcomes Disability and Rehabilitation 39: 36-42 doi: 10.3109/09638288.2016.1140831.

Webster JB, Hakimi KN, Williams RM, Turner AP, Norvell DC, Czerniecki JM (2012) Prosthetic fitting, use, and satisfaction following lower-limb amputation: A prospective study. Journal of Rehabilitation Research and Development 49(10): 1493-1504. https://doi.org/10.1682/JRRD.2012.01.0001.

Wilson E, Chen AH, Grumbach K, Wang F, Fernandez A (2005) Effects of limited English proficiency and physician language on health care comprehension. Journal of General Internal Medicine 20(9): 800-806. https://doi.org/10.1111/j.1525-1497.2005.0174.x.

Wilson RD, Lewis SA, Murray PK (2009) in Underserved Areas :
1980-2000.

You L, Sadler G, Majumdar S, Burnett D, Evans C (2012) Physiotherapists' perceptions of their role in the rehabilitation management of individuals with obesity. Physiotherapy Canada 64(2): 168-175. https://doi.org/10.3138/ptc.2011-01.

Zainal K, Salleh NM (2010) Ethnic relation among the youth in Malaysia: Toward fulfilling the concept of one Malaysia. Procedia - Social and Behavioral Sciences 9 (September 2015): 855-858. https://doi.org/10.1016/j.sbspro.2010.12.248.

Zidarov D, Swaine B, Gauthier-Gagnon C (2009) Quality of Life of Persons With Lower-Limb Amputation During Rehabilitation and at 3-Month Follow-Up. Archives of Physical Medicine and Rehabilitation 90(4): https://doi.org/10.1016/j.apmr.2008.11.003. 